\title{
User Perspective on a New Paradigm for Librarianship
}

\section{Willie L. Parson}

Myths surrounding libraries often fix the limits of the possible, sometimes to the disadvantage of the user. The centrality of the library to the academic community is questioned due to the insistence of librarians on the independent status of the library and the failure of bibliographic instruction programs to make the issue of critical thinking a top priority. A new paradigm is necessary to move libraries from their passive stance to a proactive orientation. This paradigm requires greater sensitivity to and identification with the needs of library users.

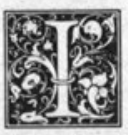

$\mathrm{n}$ his analysis of the need for change in librarianship, Paul Wasserman observed:

While present cultural conditions are critically important to every institution, they have particular meaning for the field of librarianship. For the fact of change itself, causing the turbulence which characterizes the nation, calls for appropriate support in the interest of a healthier social and political condition. The situation poses a particular challenge to an institution charged with responsibility for information dissemination. Information access is of more importance under conditions of change than in a time of stability. However, if facts are separated from fancy, the slogan from reality, the ideology of librarianship is still reflected in the passivity of its institutional forms. $^{1}$

Though this was written some twelve years ago, the significance of his message is still clear and pertinent today. Wasserman, no doubt, anticipated a time when change would proceed at a pace slower than that leading up to the publication of his book. We live, however, in an age where change is proceeding at what seems like an exponential rate, and there are no obvious and immediate signs of a slowdown. Thus, Wasserman's analysis becomes even more critical for us to reflect upon and to incorporate in our views of information access and information dissemination.

In a recent essay, Francois Jacob suggested that "myths and science fulfill a similar function: they both provide human beings with a representation of the world and of the forces that are supposed to govern it. They both fix the limits of what is considered as possible. ${ }^{\prime 2}$ It can also be said that the myths surrounding libraries and their policies often fix the limits of the possible, sometimes to the disadvantage of the user. The library, from the user perspective, is a service agency that positions itself at the center of the academic environment. Many libraries, however, do not construct programs that move beyond the limits of a simple service agency. For this reason the notion of the service agency can often be a hindering concept for many users.

That the library is the center of the academic community is a mythical concept for many college and university libraries. To the extent that librarians and library users believe this myth, the library profession constructs a variety of self-justified and self-limiting beliefs about the practices of its members, the organization of the library, and the institutional identity

Willie L. Parson is professor at Evergreen State College, Olympia, Washington 98505. This paper was presented at the ACRL Third National Conference, April 4-7, 1984, Seattle, Washington. 
of the library. Interactions of librarians with users and with other professionals within the academic community are strongly influenced by these self-justified and self-limiting beliefs.

The myth of the library being at or near the center of the academic community is maintained, paradoxically, by the insistence of librarians on the independent status of the library. That symbol of independence is a distinctive one, but it is troublesome in that it frees the library from the more obvious identifications with teaching and learning and with research (excluding, of course, research libraries). For this reason users tend to develop a view of the library that accords it a custodial function. Similarly, library personnel are often adjudged to function with interests that loom precariously close to being proprietary. An additional problem with the independent status image is that it obfuscates attempts at evaluating library effectiveness, mainly by rendering it nearly impossible to find obvious connections to real or potential sources of evaluation.

As service agencies, many libraries occupy themselves mainly with bibliographic instruction of a predictable, often dehumanizing nature. This kind of orientation to user service is codified in library policies. From a user perspective this narrowly conceived concern of the library imposes limits on function that can result in the promulgation of conservative programs and a rigidification of the custodial practices alluded to earlier. This is the kind of issue that was addressed by Mona McCormick in a recent article in which she discusses library instruction and critical thinking. McCormick suggests that the search for information "should lead students to the really interesting partdealing critically with information. The search, of course, is not an end in itself. If library education focuses only on how to locate information and on the particulars of a certain index.... it will soon bore the student who does not experience the challenge and creativity of using information critically." ${ }^{3}$

It is the failure to be concerned with the critical treatment of information that calls into question the notion of the library as the center of the academic environment. Effective pedagogy makes the issue of critical thinking a priority of the first magnitude. Only when this issue is made a toppriority agenda item in a library's programs and policies, can that library legitimately speak of its centrality to the academic environment.

As important as McCormick's article is, even she does not go far enough with her vision. Her prescription for change still largely confines library instruction to the edifice and within the context of library tours, classes, and lectures. ${ }^{4}$ A new paradigm is needed to serve user interests and to foster the idea of extending critical thinking through library service.

To advance a new paradigm a reassessment of the service agency mythology should be foremost on the agenda. Progressive policies and general library organization coupled with the imaginative application of the skills of professional librarians can offer a range of operational freedom heretofore unacknowledged.

The new paradigm must be based upon innovations that transcend merely adapting old customs and policies to library users. This becomes especially important when the users represent new clients and client groups whose demands may leap beyond the traditional demands made on libraries. Moreover, visionary planning and practice must occur if libraries are to move from their usual orthodox passive stance to a proactive orientation. This means, of course, that academic libraries may have already reached the point where they can no longer be content to wait for users' calls for service. Libraries that have not as yet made this discovery may still be shackled by the self-containment of their passive stances.

Until movement is made in the direction of adopting proactive programs, libraries will remain largely unresponsive to the needs of new client groups and will certainly find it difficult to anticipate new situations and new contingencies that impinge on library programs. The failure of libraries to be responsive to the demands imposed by minority students when minority enrollments swelled at mainstream 
institutions during the late 1960 s and early 1970 s can be attributed, in large part, to the self-containment of passive programs and practices.

Any new paradigm will also call for professional librarians to be sensitive to forces inside and outside the institutional environment that affect library users. An awareness of these forces is not sufficient. In addition, there must also be a recognition of the impact of these forces on library policy (especially regarding matters of library acquisitions). Once again, professional librarians will be confronted with a strong mandate: abandon narrowly conceived services and look to novel techniques and developmental strategies for assisting library users and for anticipating needs yet to be expressed by users. In more than a casual way this mandate will push librarians toward a form of academic engineering. This engineering should have as its manifest purpose the improvement of user output and efficiency in accessing and utilizing information, the conservation of human resources, and the humanizing of the library's impact on users of its resources.

In a recent article, Mary Huston spoke to this mandate when she suggested that research instruction might be better handled through an empowering of library users to operate from their own domain of experience rather than moving into that of the librarian's. ${ }^{5}$ Huston appropriately argues that students can draw from experiential conceptual frameworks as they do bibliographic searches, with the net result being greater receptivity and comprehension and the recognition of the applicability of the information.

Although Huston argues in favor of librarians removing themselves from the position of expert in this encounter with the user, ${ }^{6}$ it may be more appropriate for the librarian to remain in the position of expert as new paradigms of librarianship move librarians toward more proactive roles. The traditional role of the librarian and its reflection in library policy offer, from the user's perspective, a rather nonspecific invitation to make use of library services. If user-specific invitations are to be issued, then librarians may have to be- come information advocates or, to paraphrase Huston, ${ }^{7}$ sociologists of information. Thus, the librarians must assert their expertise and must act, as sociologists of information, as a nexus between the information and the user of the information who may be caught up in the turbulence of change Wasserman ${ }^{8}$ spoke of.

Such a paradigm takes on a strongly political flavor. It represents a radical point of departure from traditional librarianship. With regard to new client groups, in particular older undergraduate students, minorities, and the handicapped, any new paradigm of librarianship must account for the fact that these particular clients have personal agendas and academic agendas that are inextricably linked. Very often this is not the case for the traditional user of academic libraries, that is to say, young undergraduate students. These new client groups represent a segment of the academic community whose interests are guided by their quest for empowerment through knowledge and the acquisition of information.

Moreover, because the needs and interests of these new client groups can differ so dramatically from those of the traditional undergraduate student, the new paradigm of librarianship may also call for library programs to leave the edifice and seek out new locales where some of the services can be offered. While this, too, might seem to be a radical departure from library tradition, such an act would simply bring libraries in step with the campus mainstream. Venturing into new locales in service of new client groups would afford most libraries the opportunity to bring innovative thinking into their programs. Simultaneously, professional development might be enhanced through such ventures.

Clearly, the foregoing discussion points out the need for librarians to adopt a new paradigm in which there is a radical shift away from their strict identification with the library as an agency or institution to an identification with the client or library user. Such a shift will enhance the effectiveness of the librarian as an iniormation advocate or information-interpreting agent. It will also bring the library closer to 
actual and potential sources of evaluation. In the same light, librarians who concentrate actively on a multidisciplinary application of their expertise will find it an easier proposition to develop and implement services and programs for diverse client groups. Moreover, they will be able to step significantly beyond merely matching library users with information without intervening in the process of "valuing explanations, arguments, and critical attitudes toward facts. ${ }^{\prime \prime}$ This kind of intervention is essential to the process of students' becoming literate and developing critical and analytical perspectives.

In conclusion, let us return to Francois Jacob's essay. He says:

Whether in a social group or in an individual, human life always involves a continuous dialogue between the possible and the actual. A subtle mixture of belief, knowledge, and imagination builds before us an ever-changing picture of the possible. It is on this image that we mold our desires and fears. It is to this possible that we adjust our behavior and actions. In a way, such human activities as politics, art, and science can be viewed as particular ways of conducting this dialogue between the possible and the actual, each with its own rules. ${ }^{10}$

This is an instructive statement to librarians and to library users because it draws our attention to the importance of the role of information in establishing a dialogue between the possible and the actual. Librarians, in that aspect of their role that casts them as disseminators of information, are central participants in users' development of their sense of the actual. The users' belief structure and their ability to innovate and to be imaginative provides the basis for using this sense of the actual to conceive the possible. The participation of librarians in this dialogue should restore for them the challenges that are often negated by the self-containment of a passive role.

\section{REFERENCES}

1. Paul Wasserman, The New Librarianship: A Challenge for Change (New York: Bowker, 1972).

2. Francois Jacob, The Possible and the Actual (New York: Pantheon, 1982).

3. Mona McCormick, "Critical Thinking and Library Instruction," $R Q 22: 339-42$ (Summer 1983).

4. Ibid.

5. Mary Huston, "Rethinking Our Approach for Research Instruction," Research Strategies 1:185-86 (1983).

6. Ibid.

7. Ibid.

8. Wasserman, The New Librarianship.

9. McCormick, "Critical Thinking."

10. Jacob, The Possible and the Actual. 